\title{
A MOBILE E-TICKET FRAMEWORK FOR BUS COMMUTERS: A MAURITIAN CASE STUDY
}

\author{
Darshini Gopaul, Sandhya Armoogum and Geerish Suddul \\ School of Innovative Technologies and Engineering, University of Technology Mauritius \\ LaTour-Koenig, Pointe-Aux-Sables, Mauritius
}

\begin{abstract}
E-tickets and mobile tickets are widely used across the world for travel by air, trains and coaches. For daily commutes, smart cards are a popular mode of fare collection. These smart travel cards are re-usable and can be easily topped up but may involve a large investment which is hardly affordable in various developing countries. We therefore propose a mobile ticket-based framework which is more economically viable. Bus commuters can purchase their tickets through a mobile application which generates a unique Quick Response $(\mathrm{QR})$ code. During their trip, the QR code is scanned and validated with a corresponding mobile application. This approach considerably reduces the investment in infrastructure as opposed to smart cards. The implemented solution is flexible as it allows the mobile tickets to be used by any bus operator in Mauritius.
\end{abstract}

\section{KEYWORDS}

Mobile tickets, Mobile Application, QR code, Fare Collection

\section{INTRODUCTION}

In Mauritius, public transportation mainly consists of a bus system, where the major bus operators are the National Transport Corporation (NTC), United Bus Service (UBS), Triolet Bus Service (TBS), Rose-Hill Transport (RHT) and Mauritius Bus Transport Ltd (MBT). Mauritius, being a small island, bus travel is a convenient and popular means of transport. The bus network is widespread with around 220 bus lines and roughly 900 bus stops (NTA, 2019). Only recently, due to the increasing demand for public transport in Mauritius, the Government of Mauritius has decided to implement mass rapid transit system in the form of light rail termed "Metro Express".

E-tickets and Mobile tickets are widely used across the world for travel by air, trains and buses. For daily commutes, smart cards are popular e.g. Oyster card in London, Opal cards in Sydney, and Octopus card in Hong Kong. In the context of Mauritius, the current payment for bus travel has not evolved since its first implementation in the 1980s. Two staffs are required to work in a bus while it is servicing a particular route: a bus driver and a bus conductor. The tickets are purchased from the bus conductor using cash-only after alighting the bus. Bus ticket prices are regulated by the Government of Mauritius and implemented by the National Transport Authority (NTA) which operates under the aegis of the Ministry of Public Infrastructure and Land Transport (NTA, 2019). This mechanism of purchasing travel tickets present several inconveniences. Firstly, bus commuters are required to carry small change cash for purchase of bus tickets while travelling. However, the use of debit or credit card for payment is widely used for general retail. Secondly, given that many people use the public transport, buses are often quite full especially during peak hours whereby many people will stand during the bus journey. In such circumstances, it is quite challenging for the bus conductor to navigate among the travellers for collecting payment and also quite inconvenient for travellers to handle cash in such circumstances. This onboard fare collection naturally involves a large number of cash transactions and thus, it is also highly susceptible to fraud (i.e. bus conductor does not report the exact amount of money collected on a journey) and even theft. Moreover, this form of paper ticketing system does not support the collection of data regarding travel patterns of travellers. Finally, this form of payment is also not in line with the country's efforts towards sustainability due to the use of printed paper tickets issued to travellers. 
Very recently, since the 29th June 2017, the RHT bus operator has launched, on a pilot basis, the only contactless smart card system called "Filao" for bus ticket payment in Mauritius. The Government of Mauritius has eventually expressed interest towards a universal smart card for purchase of bus tickets with any bus operator, for the metro express as well as for taxis. It is also being debated that such a card can be used for payment of parking. As such, the Filao card can be purchased from two points (Victoria and Rose-Hill bus terminals) currently; and the card can be topped up at six points on the island using cash or debit/credit cards (TMSL, 2019). The Filao card needs to be tapped on the card reader in the bus when getting on the bus and has to be tapped again when getting off the bus. This automated bus fare payment system can definitely alleviate certain inconveniences regarding the ticket purchases as it is an easier and quicker way for purchasing tickets. However, currently the Filao smart travel card is only available on the RHT bus routes and travellers need to use one of the six top-up points to top up their card. Furthermore, a transaction statement regarding a card can only be obtained upon request by calling on a hotline number, after which the statement can be emailed to the user or collected at the card sales booths, which is not very convenient. Deploying, smart travel card systems at a national level will also involve significant investment in infrastructure i.e. all buses equipped with card readers, card sales and top-up points across the island with staff to operate the top-up points or automated top-up machines, and smart cards for the commuters amongst others. With limited financial support in developing countries, it is important to consider the use of technology for more cost-effective solutions. Thus, in this paper we describe a framework to use mobile e-tickets in the context of Mauritius for purchasing bus tickets based on a mobile application and the popular QR-code. In (Saidi Siuhi, 2016), several smart mobile applications in the area of transportations have been identified to be potentially beneficial.

This paper is organized as follows: in Section 2, we present the background study conducted which supports our proposed framework and related works. Section 3 describes the fare calculation system in Mauritius, while Section 4 describes our proposed framework and discusses its implementation. In Section 5, we discuss the benefits of the proposed framework as compared to the existing mechanism in place. In Section 6, a brief survey conducted to assess usability is presented. Section 7 concludes the paper and discusses the future work.

\section{BACKGROUND STUDY}

According to (Hootsuite, 2018), in 2018, two-thirds of the world's population have a mobile phone and more than half of the handsets in use today are "smart" devices. The mobile phone penetration in $2018(68 \%)$ is actually higher than the Internet penetration (53\%) and is on the rise. Furthermore, mobile internet users constitute $49 \%$ of the world's population. The mobile connectivity index of Mauritius is 62.7 (GSMA, 2016). Similarly, in January 2018, (Hootsuite, 2018) reported 143\% mobile connections penetration and 63\% internet penetration; $56 \%$ of the population of Mauritius are mobile internet users. This proliferation of mobile connectivity and technology has become a tool for a variety of activities in the developing world, especially given the low budget in such countries for development of services and infrastructure. Apart from its use for communication and social networking, it has several positive advantages such as contributing to the economic growth, employment, the reduction of the rural-urban differential across several developing nations around the world, to agriculture, to education and to health amongst others. As such, mobile has emerged as a platform of choice for creating, distributing and consuming innovative digital solutions and services.

The government and several companies in Mauritius have developed applications to make their products and services available online and accessible through mobile phones. Some notable examples include the Mauritius Airport App, Mauritius Traffic Alert, Smart Police Mauritius, Consumer Rights, and my.t Weather. Numerous mobile applications are also available regarding shopping in Mauritius. Mobile banking is also quite present on the island (Ramdhony \& Munien, 2013). Unfortunately, there are currently no mobile services regarding the purchase of travel tickets in Mauritius. However, based on the above discussion, it is clear that Mauritius is ready for such an initiative. Mobile tickets are already popular for air tickets, sports and cultural events worldwide. For instance, Barcelona is in the phase of improving its public transport by the introduction of T-mobilitat chip card for contactless validation as well as supporting mobile app using NFC technology (T-Mobilitat, 2018). Similarly, many European countries - which are already using smart 
cards - are now also enhancing their services via mobile applications. In (Ferreira, et al., 2014), the authors also proposed a cost-effective public transport ticketing solution based on mobile devices such that minimal investment is incurred.

\section{BUS FARE IN MAURITIUS}

There are 305 bus routes in Mauritius which are serviced by the following bus operators/owners/co-operative societies: NTC, UBS, TBS, RHT, MBT, and Individual Operators (IO) (NTA, 2019). The bus ticket prices are regulated by the Government of Mauritius. Thus, bus tickets are the same irrespective of the bus operator and some bus routes are serviced by more than one bus operator. The bus fare is calculated based on distance travel in Mauritius, according to the number of fares stages travelled, where each fare stage is about $1.6 \mathrm{~km}$. Each route consists of varying number of fare stages, which coincide with bus stops along the routes. A sample of the most recent bus fare as at August 2013 is shown in Figure 1 (a). As in most countries, there are concessionary fares for the following categories of passengers: (1) Children, and (2) Students. Pensioner or disabled person is issued a travel pass by the Ministry of Social Security, which authorize them to travel free of charge as from $15^{\text {th }}$ August 2005. Figure 1 (b) depicts the stage information for the Route 1A which connects Port Louis (Victoria Square) to Rose-Hill (Market). The bus fare is simply computed by finding the number of fare stages travelled by the passenger i.e. disembarkation stage number minus the embarkation stage number, and then using the fare stage table. For example, a passenger travelling on Route 1A alighting the bus at the bus stop Brabant (SPAR) and disembarking at Rose Hill (Market), would have travelled 8 stages. Finding the passenger fare is just a simple lookup in the Bus Fare Stage table depicted in Figure 1 (a). The adult passenger fare would be Rs 30 , while the fare for a child travelling the same journey would be Rs 16.

$\begin{array}{cccc}\text { Stage No. } & \begin{array}{c}\text { Adult } \\ \text { Rupees }\end{array} & \begin{array}{c}\text { Child } \\ \text { Rupees }\end{array} & \begin{array}{c}\text { Student } \\ \text { Rupees }\end{array} \\ 1 & 12.00 & 7.00 & 12.00 \\ 2 & 18.00 & 10.00 & 12.00 \\ 3 & 24.00 & 12.00 & 17.00 \\ 4 & 24.00 & 12.00 & 17.00 \\ 5 & 27.00 & 14.00 & 17.00 \\ 6 & 27.00 & 14.00 & 17.00 \\ 7 & 30.00 & 16.00 & 17.00 \\ 8 & 30.00 & 16.00 & 17.00 \\ 9 & 31.00 & 17.00 & 17.00 \\ 10 & 31.00 & 17.00 & 17.00 \\ 11 & 31.00 & 17.00 & 17.00 \\ 12 & 31.00 & 17.00 & 18.00\end{array}$

\begin{tabular}{|c|l|c|c|}
$\begin{array}{c}\text { Fare } \\
\text { Stage }\end{array}$ & \multicolumn{1}{|c|}{ Locality } & $\begin{array}{c}\text { Average } \\
\text { Journey } \\
\text { Times in } \\
\text { minutes }\end{array}$ & $\begin{array}{c}\text { Fare } \\
\text { Stage }\end{array}$ \\
\hline 0 & Port Louis (Victoria Square) & & 0 \\
\hline 1 & Brabant (SPAR) & 6 & 1 \\
\hline 2 & G.R.N.W. & 13 & 2 \\
\hline 3 & Coromandel (Sunray Hotel) & 18 & 3 \\
\hline 4 & Belle Etoile (Tamil Social Hall) & 21 & 4 \\
\hline 5 & Beau Bassin (Vinayak Mandir) & 25 & 5 \\
\hline 6 & $\begin{array}{l}\text { Beau Bassin (Serge Alfred } \\
\text { Swimming Pool) }\end{array}$ & 35 & 6 \\
\hline 7 & $\begin{array}{l}\text { Hugnin Road (Rose Hill } \\
\text { Transport Garage) }\end{array}$ & 40 & 7 \\
\hline 8 & $\begin{array}{l}\text { Boundary Road (St Patrick } \\
\text { Church) }\end{array}$ & 47 & 8 \\
\hline 9 & Rose Hill (Market) & 50 & 9 \\
\hline
\end{tabular}

(a)

(b)

Figure 1. (a) Extract of Bus Fare Stage for Adult, Child and Student as at 12th August 2013 (NTA, 2019)

(b) Bus Route 1A Port Louis (Victoria Square) to Rose Hill (Market) (NTA, 2019)

\section{PROPOSED FRAMEWORK}

\subsection{Architecture and Design}

The proposed framework aims to facilitate travelling by bus in Mauritius by introducing mobile tickets for bus travellers via the MoTicket mobile application. This mobile application allows travellers to buy their travel tickets before travelling, thereby avoiding the need to perform cash payment on the bus. The fare calculation is as per the government regulation as described in Section 3 and the mobile ticket can be used 
when travelling via any bus operator. Payment of tickets online can be done by debit/credit card, via mobile payment (e.g. MCB Juice, Orange Money) or by PayPal. Each individual ticket can be used once and, for flexibility, tickets bought have a validity period, after which the ticket is no longer valid. The proposed framework architecture is as depicted in Figure 2. Figure 3 shows a few user interfaces. The system consists of the following main components: a smart mobile device for the client side (used by traveller), a smart mobile device as ticket scanner (used in bus), a database server for storing information, and a web server for computing fare and for handling payment of tickets. The system administrator(s) can use a web browser to login to the server for entering/updating fare, route information, bus stop, driver information, ticket type, etc.

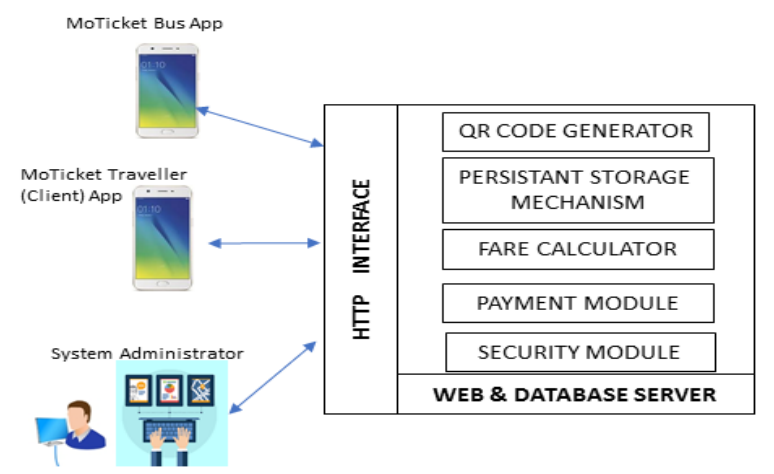

Figure 2. System Architecture
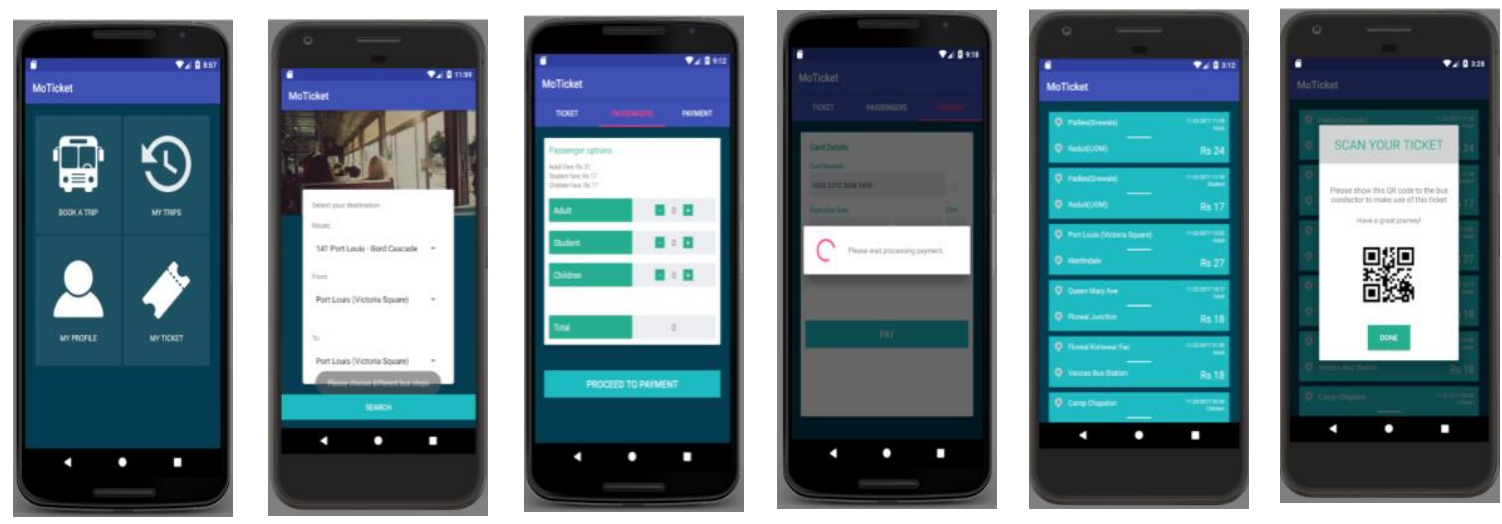

Figure 3. User Interfaces

\subsection{QR Code for Securely Storing Information for the Mobile Ticket}

Quick Response (QR) codes are widely used today as they provide faster and easy readability independent of their orientation than traditional barcodes. QR codes can also store a large amount of information in a compact fashion as compared to traditional barcodes, Near Field Communication (NFC) and RFID. They have error correction capability and are less prone to physical damages which make them more robust for storing information. QR codes can be used to store text, video, advertisement, personal information, URL, business card information or any type of digital information. As mobile technologies are booming, QR codes are being used for various purposes such as for accessing information on the web, for discount coupons, for interacting with social media, for mobile marketing, smart labelling (Ramalho, et al., 2018), for tickets (Kadge, et al., 2017), and for enhancing government service (Lorenzi, et al., 2014), amongst others. NFC is an alternative for contactless interaction (validation of tickets), however it may not be available on all smart phones. Moreover, NFC is known to have security issues such as eavesdropping whereby data from the mobile phone could be stolen, manipulation of data being transmitted, insertion of fake data, 
man-in-the-middle attack whereby the attacker acts as a middleman between two NFC devices to intercept the data, and denial of service attack whereby the attacker can disrupt the communication between two devices. In this proposed framework, QR code is thus used for implementing mobile tickets for bus payment. The mobile ticket consists of the data as shown in Table 1. All data components, excluding the status byte, are concatenated and the resulting output is hashed using the SHA512 algorithm. The hash value is then encrypted using the private key of the server to generate the signature of the ticket, which allows checking the authenticity and integrity of the ticket. All ticket data including the signature is to be encoded and stored as QR code for the mobile ticket.

Table 1. Mobile Ticket Data

\begin{tabular}{llcl}
\hline Ticket Data & Data Type & Bytes & Remarks \\
\hline TicketID & Numeric & 1 & Uniquely identifies the ticket \\
UserID & Numeric & 1 & Uniquely identifies the user who bought the ticket \\
TicketTypeID & Numeric & 1 & Indicates the type of ticket (Adult, Child, Student) \\
StartStopID & Numeric & 1 & Uniquely identifies the embarkation stop \\
EndStopID & Numeric & 1 & Uniquely identifies the dis-embarkation stop \\
No. of routes & Numeric & 1 & Indicates the no. of routes for which the ticket is valid. \\
Routes & Alphanumeric & 10 & Indicates routes on which ticket can be used \\
No. of Stages & Numeric & 1 & Indicates the number of fare stages of the journey \\
Fare & Numeric & 1 & Indicates fare amount paid for ticket \\
Expiry Date & Numeric & 4 & Day/Month/Year \\
Status & Binary/Byte & 1 & Unused ticket status 1, Used ticket status 0 \\
Hash Value & Byte & 128 & SHA512 hash algorithm used. The hash value is stored as 128 \\
& & & hexadecimal numbers in the ticket \\
Signature & Byte & 256 & Hash value encrypted using private key of server (RSA Algorithm \\
& & & with a key of 2048 bit key) to generate the Signature \\
\hline
\end{tabular}

\subsection{Creating QR Code}

When encoding data into a QR code, three parameters have to be selected: the encoding mode, the version, and the error correction level.

Determining Encoding. A QR code usually encodes a string of text into a string of binary digits by using one of the following modes: (1) numeric, (2) alphanumeric, (3) byte or UTF-8, and (4) Kanji. The ticket information mainly consists of numeric data as shown in Table 1; except for the hash value and signature, which are non-numeric. In the proposed framework, the mobile ticket data is encoded using UTF-8, which is a variable width character encoding capable of encoding all 1,112,064 valid code points in Unicode using one to four bytes.

Determining Version. The size of the QR code is called the version. The smallest QR codes are $21 \times 21$ pixels (version 1), and the largest are $177 \times 177$ (version 40). Version 40 can carry the largest amount of information. Usually, the smallest version has to be determined for storing the data to be encoded. The storage capacity of QR codes however, also depends on the type of data being stored. Most of the ticket data are numeric values and can be effectively represented and stored as 1 byte of information as shown in Table 1. A particular journey may be undertaken on several bus routes if the path of one route overlaps partially and/or completely with the path of another route. In the proposed framework, it is assumed that the maximum number of routes which satisfy the overlap criteria for a journey is 5 . Thus, the number of bytes for storing the routes for which the ticket is valid is assumed to be a maximum of 10 bytes (each route requiring a maximum of 2 bytes to store the information). The storage of the date requires 1 byte each for the storage of day and month respectively and 2 bytes for storing the year, thus a total of 4 bytes. For computing the hash value, the SHA512 hash algorithm is recommended. This algorithm generates fixed length hash values of 
size 512 bits, which is to be stored in the ticket as 128 hexadecimal numbers thus requiring 128 bytes. The signature is generated by encrypting the hash value with an RSA algorithm and key of 2048 bits, thus the signature size being 2048 bits, is equivalent to 256 bytes. The total amount of ticket information to be encoded is thus 407 bytes. The smallest version of QR code which can encode the ticket data is version 13 (69x69).

Determining Error Correction Level. QR codes provide error correction by means of the ReedSolomon (RS) error correcting codes. This redundant data helps the QR reader accurately read the code even if part of it is unreadable. There are four levels of error correction: L, M, Q, H. The higher levels of error correction, the better the error detection and correction capability, however it also requires more redundant bytes resulting in a larger QR code. Version $22(105 \times 105)$ and onwards (till Version 40$)$ could be used to encode the 407 bytes of ticket data with the highest error correction. The QR code being stored on the mobile phone (no major risk of damage e.g. torn, blurred,...), it is believed that a medium error correction level provides adequate recoverability. For scalability and flexibility (i.e. allowing for additional data if required in the future), the version 17 is used.

QR Code Generation. After payment has been received, the mobile ticket containing such a $\mathrm{QR}$ code is generated by the server and sent to the user's mobile device.

\subsection{Validating the QR code/Mobile ticket}

Usually, in countries making use of smart cards or mobile tickets, QR code readers are fixed in the bus or handheld QR code readers are used. But such hardware devices have some financial implications. Today, QR code reader apps are readily available on mobile phones. In the proposed framework, a smart mobile phone with the MoTicket Scanner Bus app is to serve as the QR code reader to validate the mobile ticket. Mobile tickets can also be verified visually, by the bus conductor, as application displays all the information which is encoded in the QR code. This solution is most economic and can be very quickly deployed. Such a mobile app scans the QR code and read the encoded data. Given that smart phones nowadays have good processing power and adequate storage capacity; the app is designed to validate the ticket locally to reduce the network dependence thereby reducing the cost of data connectivity. The MoTicket Bus Scanner mobile app also regularly connects to the server to update the tickets status information about the validated tickets such that such validated tickets cannot be re-used. Before starting to service a route, the bus conductor logs in and sets the bus operator and bus route, whereby the mobile application downloads all the bus stops (StopID) for the selected route from the server and saves this information on the mobile phone in a suitable data structure (e.g. SQLite on Android). The bus route information is required to allow the application to validate tickets.

\section{POTENTIAL BENEFITS AND LIMITATIONS OF PROPOSED FRAMEWORK}

The proposed framework for mobile bus ticketing in Mauritius offers numerous benefits as follows:

(1) Increased user satisfaction and convenience: Travellers do not have to handle monetary transaction while on the bus and they also have the flexibility of buying their tickets anytime and anywhere from their mobile phone unlike in the case of the Filao smart travel card system whereby the travel card can be topped up at specific points. Via the mobile application, local travellers and even tourists can quickly search for a bus route and find the cost of the bus tickets for any journey. Travellers have a "Wallet" where they can view valid tickets and a "Travel History" where they can view used tickets and journeys.

(2) Ease of validation of the mobile ticket by the bus conductor: The bus conductor using a smart phone can quickly scan and validate the mobile tickets as passengers' board the bus. The mobile ticket will most definitely drastically reduce the need to handle cash.

(3) Bus operator independence: Given that the cost of travel by bus is regulated by the government and is the same irrespective of the bus operator, the mobile app allows travellers to select their bus trip and to 
buy tickets. Such tickets can be used on any bus operator. The system keeps track of the operator which validates the ticket and the payments received from the travellers transferred to the specific operator.

(4) Green and Cashless economy: The proposed framework promotes a cashless economy and provides a safer way for purchasing tickets and reduces fraud or theft. It also promotes a green economy due to the decrease of paper-based tickets.

(5) Scalable and quickly deployable: The proposed system is scalable and can accommodate the growing number of travellers in urban regions. Furthermore, once the mobile ticketing system is implemented, the mobile apps can be made available for download easily and instantaneously for use by bus travellers.

(6) Low Capital Expenditure (CapEx): Less investment in infrastructure in terms of hardware is required to implement the mobile ticketing. The use of smart phones for ticket validation by the bus conductor, a backend server, and a database server is the basic requirements.

(7) Better monitoring and reporting: The mobile ticketing framework as compared to the traditional ticket system, offers better insights regarding transportation statistics. Data collected from the system can be mined and be valuable to understand travel patterns. This analysis can be used for effective management when planning and scheduling new bus routes, and bus frequencies on different days and times. This can greatly help the bus operator optimize their running costs.

(8) Enhanced services to customers: The mobile application using the smart phone features can be extended to offer additional services such as real-time bus tracking via an interactive map, as well as other similar services.

However, the proposed framework for mobile bus ticketing in Mauritius also involves certain limitations such as the dependency on the mobile data network connection. The bus app needs to communicate with the server frequently to update information about validated bus tickets. However, there are certain small areas where the mobile connectivity may not be reliable. This can incur a delay in communication with the server. Moreover, the cost of mobile data connectivity is also an important Operational Expenditure (OpEx) consideration. The network operators may be reluctant to bear the cost of the data connection. Travellers are also required to have mobile connectivity for purchasing tickets.

\section{SURVEY}

An online survey was carried out to evaluate the acceptance of the proposed framework by university students of the age group 18-30 who travel by bus at least once a day, of which $63 \%$ were male and $37 \%$ were female. All respondents possessed a smart phone and had internet connectivity as follows: $85.2 \%$ use both Wi-Fi and Mobile data, while $14.8 \%$ use only Wi-Fi for internet connectivity. Thus, it can be concluded that users mostly have connectivity. Apart from the respondent themselves, $81.4 \%$ of the respondent reported that one or two persons from their home also uses the bus at least once daily. All the respondents were 100\% positive about their intention to use the mobile app for buying their bus tickets and about the usefulness and ease of use of the application. They all agreed that the framework would make travel by bus easier and that the information provided regarding the costs of tickets was useful. Most respondents preferred the micro payment mechanism (MCB Juice and Orange Money) for purchasing bus tickets. Figure 4 summarizes the result of the a few questions in the survey.

In (Ferreira, et al., 2013), a more in-depth study, with a small sample of the population, was conducted for the mobile ticket system proposed for Porto City in Portugal to assess the user acceptance of system. The results indicate that users found the mobile app based ticket purchase and validation easy to use, useful, convenient and informative, while perceived risk and complexity was deemed low by respondents. Another, more recent study was conducted to assess the mobile payments adoption in public transport in the medium-sized metropolitan area of Porto as compared to the large metropolitan area of Beijing, China (Fontes, et al., 2017). It was observed that the mobile payment for purchase of public transport tickets was greatly accepted in both cities and has high potential market (30-68\%), even though the Chinese people showed a higher motivation. These studies further support the acceptance of the proposed framework by travellers. 


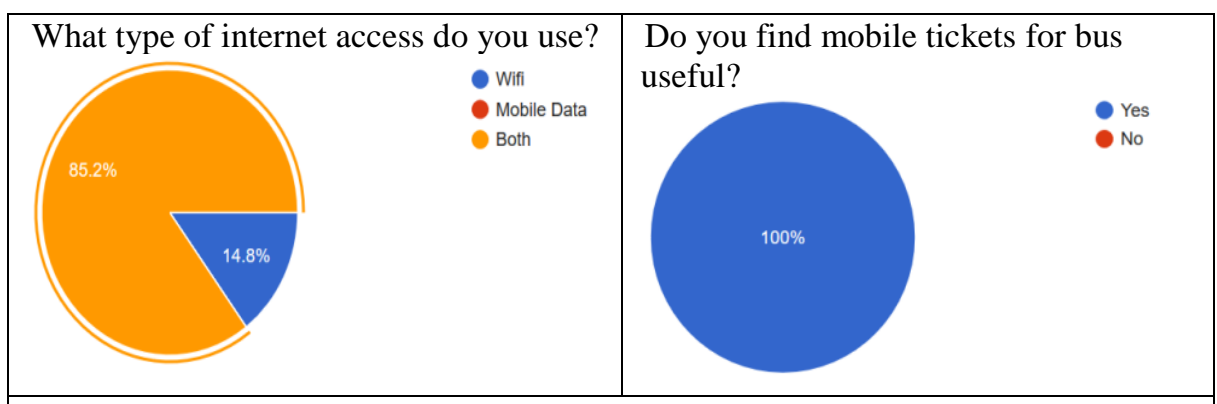

What is the main need in your house for bus transport? (Please tick any of the answers that apply to you and people in your house.)

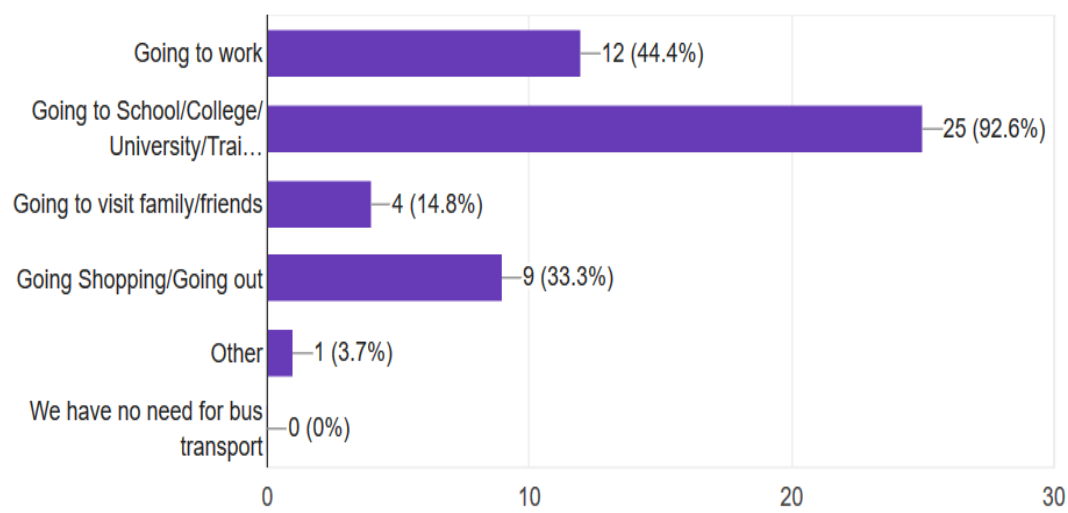

Which method would you prefer for paying for bus tickets on your mobile phone? (Please tick any of the answers)

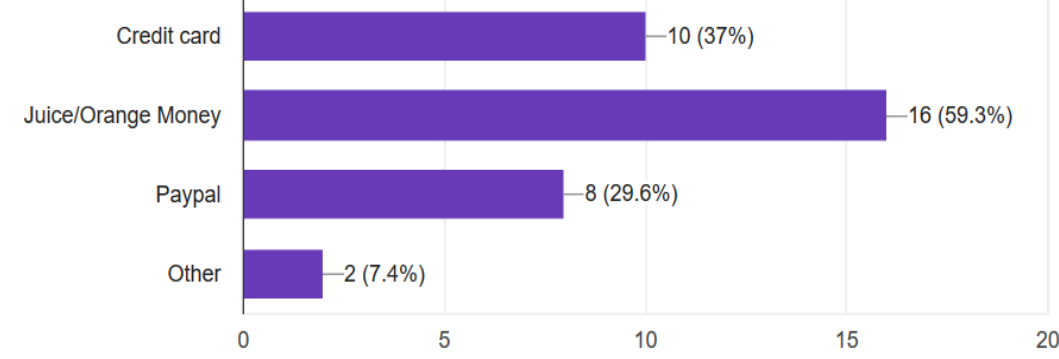

Will using mobile ticket makes traveling by bus easier? (1 Strongly Disagree, 5 Strongly Agree)

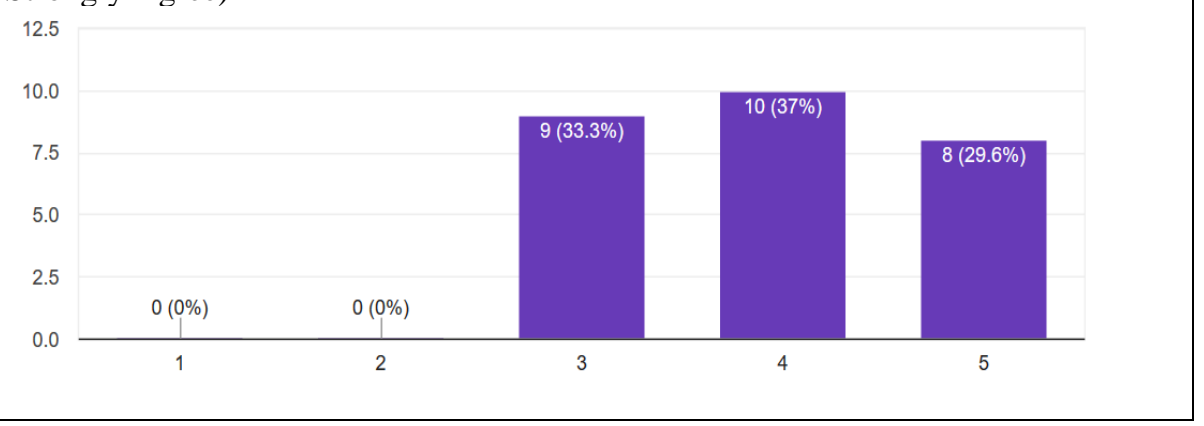

Figure 4. Survey Results 


\section{CONCLUSION}

Currently, public transport in Mauritius has remained unaddressed until recently where the Metro Express project has been initiated by the government of Mauritius in 2018. Similarly, bus ticketing in Mauritius has not changed since its implementation until June 2017 where one bus operator has introduced smart travel card. Several developing countries in Asia and Sub-Saharan Africa are in a similar situation. The main motivation of the proposed framework has been to provide a new service offering in the form of mobile ticketing which may replace or complement the traditional public transport to provide efficient, economically feasible, easily deployable, and modern system to meet the mobility needs of people. The implemented prototype was showcased to a group of students who travel by bus on a daily basis and positive feedback was obtained. The adoption of e-services in Mauritius is on the rise where citizens are filing tax online, using the numerous government e-services, engaging in online shopping and actively participating on social media networks. Thus, the adoption of the mobile bus ticketing service by the general population is promising in Mauritius. Such a framework could be easily adopted by several developing countries in Africa to complement their existing fare collection system. Data inherently collected in the long run can be analyzed to help bus companies to enhance their policy regarding optimized organization of their bus fleet schedule.

Future work involves improving the proposed framework to add more flexibility such as the possibility of purchasing return tickets or a weekly travel ticket. For the payment of tickets, the use of existing traditional mechanism such as credit card payments seems overrated especially given that bus fares often involve small amount of money. More micro-payment mechanisms are to be investigated as the payment mode as well as extended services such as real-time bus tracking.

\section{REFERENCES}

Ferreira, et al., 2014. A proposal for a public transport ticketing solution based on customers' mobile devices.. Procedia - Social and Behavioral Sciences, Volume 111, p. 232 - 241.

Ferreira, M. C., Nóvoa, M. H. \& Dias, T. G., 2013. A Proposal for a Mobile Ticketing Solution for Metropolitan Area of Oporto Public Transport. In: J. F. e. C. M. S. H. Nóvoa, ed. Lecture Notes in Business Information Processing: Exploring Services Science. Berlin Heidelberg: Springer-Verlag, p. 263-278.

Fontes, T. et al., 2017. Mobile payments adoption in public transport. Transportation Research Procedia, Volume 24, p. $410-417$.

GSMA, 2016. Mobile Connectivity Index. [Online] Available at: https://www.mobileconnectivityindex.com/\#year=2016\&globalRankings=overall\&globalR [Accessed 27 January 2019].

Hootsuite, 2018. Digital in 2018. [Online] Available at: https://hootsuite.com/pages/digital-in-2018_[Accessed 27 January 2019].

Kadge, S., Sayyed, S., Buwa, B. \& Madraswala, B., 2017. M-Ticketing System using QR Codes for Mumbai Local. International Journal of Computer Applications, 162(11).

Lorenzi, D. et al., 2014. Enhancing the government service experience through QR codes on mobile platforms. Government Information Quarterly, 31(1), pp. 6-16.

NTA, 2019. National Transport Authority (NTA) Bus Routes. [Online] Available at: http://nta.govmu.org/English/Procedures/Documents/Bus-TimeTable_[Accessed 27 January 2019].

Ramalho, J. F. et al., 2018. Luminescent QR codes for smart labelling and. Optics \& Laser Technology, Volume 101, pp. 304-311.

Ramdhony, D. \& Munien, S., 2013. An Investigation on Mobile Banking Adoption. World Journal of Social Sciences, 3(3), p. $197-217$.

Saidi Siuhi, J. M., 2016. Opportunities and challenges of smart mobile applications. Journal of traffic and transportation engineering (English Edition), 3(6), pp. 582-592.

T-Mobilitat, 2018. Intelligent Mobility. [Online] Available at: https://www.tmb.cat/en/abouttmb/ [Accessed 4 December 2018].

TMSL, 2019. Introducing Filao Automatic Bus Fare Collection. [Online] Available at: http://tmsl.mu/ [Accessed 27 Jan 2019]. 